\title{
Basidiospores of Rust Fungi (Uromyces Species) Differentiate Infection Structures in Vitro
}

\author{
Sibylle Freytag, Letizia Bruscaglioni, Randall E. Gold, ${ }^{1}$ and \\ Kurt Mendgen \\ Universität Konstanz, Fakultät Biologie, Lehrstuhl Phytopathologie, D-7750 Konstanz, \\ Federal Republic of Germany
}

Accepted for publication April 5, 1988

\begin{abstract}
Freytag, S., Bruscaglioni, L., Gold, R. E., and Mendgen, K. 1988. Basidiospores of rust fungi (Uromyces species) differentiate infection structures in vitro, Experimental Mycology 12, 275 283. The effect of six different substrates on basidiospore germination and differentiation of infection structures was investigated in three species of Uromyces: $U$. appendiculatus var. appendiculatus, $U$. viciae-fabae, and $U$. vignae. Light and fluorescent microscopic observations were made after 3 days of incubation on the following substrates: 2 or $5 \%$ water agar, glass slide, collodion membrane, nitrocellulose sheet, and isolated host cuticle. Infection structure development up to the formation of a primary hypha was observed on hard substrates, such as $5 \%$ water agar, nitrocellulose sheet, and on isolated host cuticle. Addition of oil to the collodion membrane did not significantly increase the differentiation rate. The morphology and nuclear condition of these basidiospore infection structures were similar to those observed in host tissue. For the three directly penetrating species we studied, it appears that basidiospores respond to an unspecific stimulus, such as the thickness of host cuticle or the hardness of an artificial substrate.
\end{abstract}

INDEX DESCRIPTORS: basidiospores; infection structures; rust fungi; Uromyces.

Urediniospores and basidiospores of rust fungi typically penetrate and infect their host plants in different ways (Littlefield and Heath, 1979). Germ tubes of dikaryotic urediniospores normally form appressoria over stomata and penetrate with an infection peg. Once in the substomatal chamber, the fungus differentiates a vesicle from which arise one or more elongated infection hyphae. After the formation of haustorial mother cells, intracellular haustoria develop in host cells. In contrast, mono- or binucleate basidiospores penetrate into epidermal cells directly via appressoria, that generally occur close to the anticlinal walls of the epidermis. After penetration of the cuticle and cell wall, a vesicle develops within the epidermal cell without disrupting the host plasmalemma. This intraepidermal

\footnotetext{
${ }^{1}$ Present address: BASF AG, Landwirtschaftliche Versuchsstation, D-6703 Limburgerhof, FRG.
}

vesicle elongates into a primary hypha that may branch and grow into adjacent epidermal and palisade cells or exit from the epidermal cell into the intercellular space (Fig. 1). Only recently has the ultrastructure of the early basidiospore infection process been described in Gymnosporangium fuscum (Metzler, 1982), Cronartium quercuum f. sp. fusiforme (Gray et al., 1983), and Uromyces appendiculatus var. appendiculatus (Gold and Mendgen, 1984).

Since 1949 it has been possible to induce in vitro the formation of infection structures from urediniospores of numerous rust fungi on collodion membranes with oil inclusions (Dickinson, 1949). More recently, Wynn (1976) and Staples and Macko (1980) used scratched glass and polyethylene sheets to induce urediniospore differentiation. With all these methods, however, the differentiation process only continues up to the formation of the infection hypha or in some 


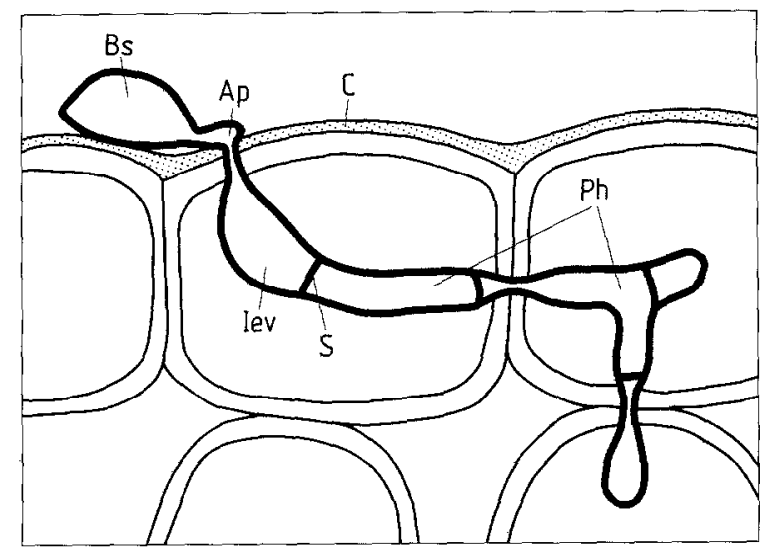

FIG. 1. Schematic representation of basidiospore infection structures in cross section of a host leaf (Bs, basidiospore; Ap, appressorium; Tev, intraepidermal vesicle; $\mathrm{S}$, septum; $\mathrm{Ph}$, primary hypha; $\mathrm{C}$, cuticle).

cases up to the haustorial mother cell (Heath and Heath, 1978). The formation of typical intracellular haustoria in vitro has never been observed.

In the present paper we report on the in vitro induction of intracellular infection structures which normally differentiate in living host cells during the haploid phase of Uromyces species rust fungi.

\section{MATERIAL AND METHODS}

Teliospores of Uromyces appendiculatus (Pers.) Unger var. appendiculatus were collected from naturally infected garden beans (Phaseolus vulgaris L.) in the field, overwintered outside for about 4 months in jute sacks, and then stored at $4^{\circ} \mathrm{C}$ as described previously (Gold, 1983). The original uredinial culture of $U$. viciae-fabae (Pers.) Schroet. was also obtained from naturally infected host plants and urediniospores of $U$. vignae $\mathrm{Barcl}$, were kindly provided by Dr. M. C. Heath, University of Toronto. Teliospores of $U$. viciae-fabae and $U$. vignae were increased on susceptible faba bean (Vicia faba L.) and cowpea (Vigna sinensis (L.) Endl.), respectively, in growth chambers as described earlier for the bean rust fungus (Gold and Mendgen, 1983). Since both species are leptotypes they were stored at $4^{\circ} \mathrm{C}$ directly after collection.

Methods for induction of teliospore germination were modified after Gold and Mendgen (1983). Teliospores of $U$. appendiculatus var. appendiculatus were incubated on cellulose nitrate filter in petri dishes for 7 days in darkness at $18^{\circ} \mathrm{C}$ and 100\% RH and then given $1 \mathrm{~h}$ light (ca. 13000 lx). Approximately $7 \mathrm{~h}$ thereafter basidiospores were released (Fig. 2a). For the latter two species, teliospores were incubated under a 16-h daily photoperiod at $18^{\circ} \mathrm{C}$ and $100 \%$ RH. After about 3 days of rehydration, teliospore germination ensued and basidiospores were released (Fig. 2b).

Activated teliospores were mounted in the lid of a petri dish moist chamber, such that the basidiospores were released onto the different substrates (Fig. 3). We tested (a) 2 and 5\% water agar (Noble Agar, Difco); (b) glass slides; (c) artificial membranes: nitrocellulose P250 (Bemberg Folien, Wuppertal, FRG), polyethylene (Frischhaltefolie and Gefrier-Beutel, Melitta-Werke Bentz \& Sohn, Minden, FRG), collodion without paraffin oil, and collodion with 5 or $10 \mu \mathrm{l} / \mathrm{ml}$ paraffin oil (after Wynn, 1976); and (d) cuticles obtained from host leaves by enzymatic digestion $(0.5 \%$ Macerozym, $2 \%$ cellulase Onozuka 

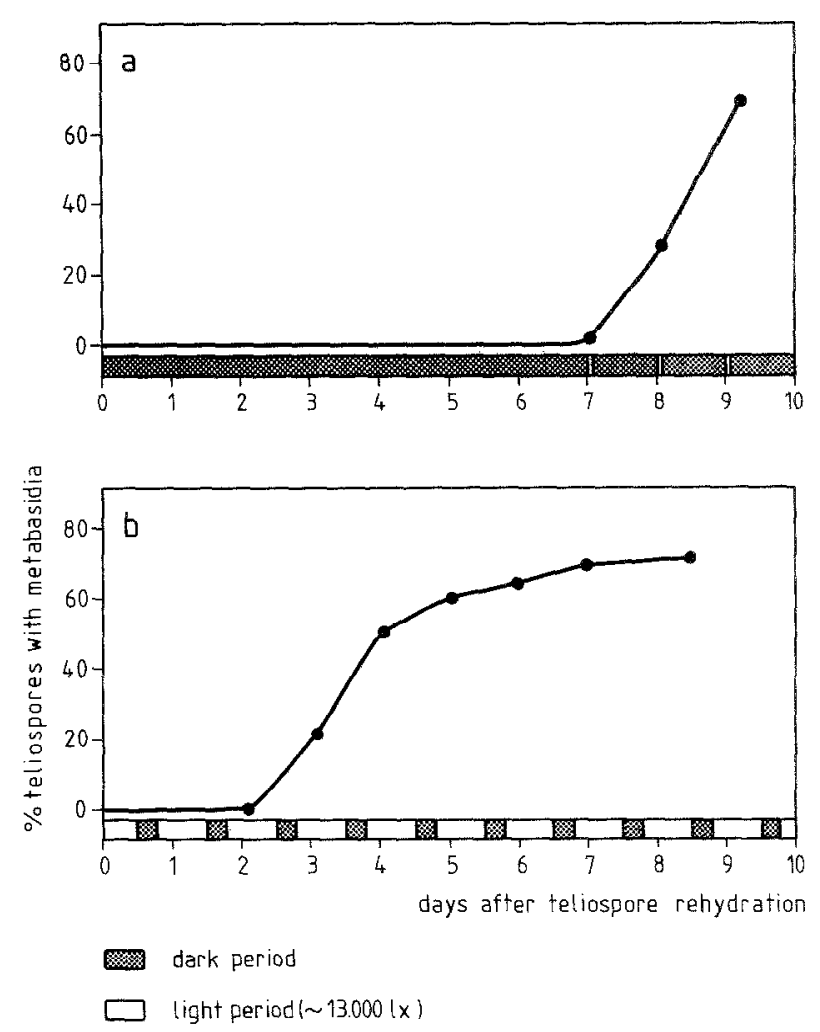

FIg. 2. Basidiospore release in vitro from teliospores of (a) Uromyces appendiculatus var. appendiculatus following a 1 -h exposure to light and (b) $U$. viciae-fabae during 3 days of incubation. Both species were incubated at $18^{\circ} \mathrm{C}, 100 \% \mathrm{RH}$.

$\mathrm{R} 11$, and $1 \%$ pectinase in distilled water; all substances from Serva, Heidelberg, FRG). Glass slides, artificial membranes, and cuticles were tested on $2 \%$ water agar in petri dishes. The samples were covered with a mist of water before incubation.

After 3 days of incubation, samples were mounted on slides and stained with $0.1 \%$ $(w / v)$ trypan blue in lactophenol:glycerol: water $(1: 1: 1)$ for differential-interference-contrast microscopy. For each treatment $4 \times 100$ spores were scored for ger- mination and differentiation; each experiment was repeated at least three times.

Nuclear behavior of germinated and/or differentiated basidiospores was studied by fluorescence microscopy. Samples were stained with $5 \mu \mathrm{l} / \mathrm{ml}$ DAPI (4,6-diamidinophenylindol $\cdot 2 \mathrm{HCL}$, Serva) in $0.05 \mathrm{M}$ phosphate buffer, $\mathrm{pH} 7.2$, for $5 \mathrm{~min}$ and then with $0.02 \%$. $(\mathrm{w} / \mathrm{v})$ Calcofluor for $2 \mathrm{~min}$ after fixation in $2 \%(\mathrm{v} / \mathrm{v})$ glutaraldehyde in phosphate buffer for $20 \mathrm{~min}$. Observations were made with a Standard Zeiss incident

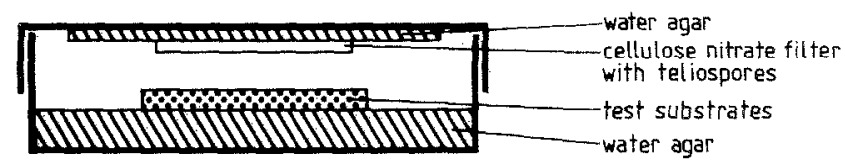

FIG. 3. Schematic representation of moist chamber used for teliospore germination and release of basidiospores on various substrates. 
fluorescence microscope. A 365-nm excitation filter and 420-nm barrier filter were used.

Fluorescence microscopy of inoculated host leaves was done using the methods described by Rohringer et al. (1976), with the exception that the fungus was stained with $0.2 \%(\mathrm{w} / \mathrm{v})$ diethanol (Uvitex 2B, CibaGeigy).

\section{RESULTS}

Teliospores of Uromyces appendiculatus var. appendiculatus were successfully activated after 7 days of rehydration in the dark. After the initial light signal of $1 \mathrm{~h}$, approximately $30 \%$ of the teliospores were germinated $7 \mathrm{~h}$ later. After the second light signal, an additional $30 \%$ of the teliospore population produced metabasidia (Fig. 2a). This method allowed initiation of the teliospore germination process at any defined time. Teliospores of $U$. viciae-fabae and $U$. vignae germinated and released basidiospores within 3 days after rehydration (Fig. $2 b)$. In these species, teliospore germination was not influenced by the photoperiod (data not shown).

Basidiospores germinated rapidly after landing on test surfaces. On most substrates the rate of ungerminated basidiospores was below $10 \%$, except for glass slides where it was significantly higher (Table 1).

On $2 \%$ water agar, basidiospores with long germ tubes $(50-100 \mu \mathrm{m})$ predominated. Even after 3 days of incubation, differentiation was not observed (Fig. 4). In contrast, infection structures were induced in all species when incubated on 5\% water agar (Table 1). The short germ tubes swelled apically and formed a small appressorium, not separated from the germ tube by a septum. Subsequently, a penetration peg formed and an oblong vesicle expanded in the agar (Fig. 5). With U. appendiculatus var. appendiculatus and $U$. vignae, the induction of appressoria was very high. Fur- thermore, the percentage of basidiospores which differentiated up to the vesicle stage was also high, 32 and $16 \%$, respectively. In contrast, the response of basidiospores of $U$. viciae-fabae was significantly poorer with only $15 \%$ appressoria and $3 \%$ vesicles differentiated (Table 1).

On glass slides appressorium formation often occurred in $U$. viciae-fabae and $U$. vignae; however, vesicles were rarely observed. Basidiospore germination in U. appendiculatus var. appendiculatus was significantly lower on glass slides than all other treatments.

Basidiospore germlings differentiated on artificial membranes mounted on $2 \%$ water agar. The infection peg of the appressorium never penetrated the substrate. The vesicles and primary hyphae formed directly on test surfaces in all Uromyces species. With polyethylene sheets (data not shown) or collodion membranes, appressorium formation occurred, but the rate of vesicle and primary hypha formation remained between 8 and 16\% (Table 1). Adding different amounts of paraffin oil to collodion membranes did not significantly increase the percentage of vesicles.

Basidiospore differentiation was most effectively induced on nitrocellulose membranes. Less than $5 \%$ of the germinated basidiospores had long germ tubes and nearly all basidiospores reached the appressorium stage. Depending on the species, 13 to $33 \%$ of the population differentiated a vesicle and sometimes a primary hypha (Figs. 6 and 7); however, further development did not occur.

Similar results were obtained with host leaf cuticles mounted on $2 \%$ agar (Table 1). However, with this method, basidiospore germlings of $U$. viciae-fabae usually penetrated the cuticle after appressorium formation. The vesicle, which appeared morphologically similar to the intraepidermal vesicle commonly observed in vivo (cf. Fig. 11), grew below the cuticle into the agar (Fig. 8). U. appendiculatus var. appendiculatus and 
TABLE 1

Effect of Different Surfaces on Basidiospore Differentiation in Three Uromyces Species after 3 Days of Incubation

\begin{tabular}{|c|c|c|c|c|}
\hline \multirow{3}{*}{$\overline{2} \%$ agar } & \multicolumn{2}{|c|}{ Basidiospore } & \multicolumn{2}{|c|}{ Differentiation up to } \\
\hline & Ungerminated & $\begin{array}{l}\text { With } \\
\text { germ tube }\end{array}$ & Appressorium & $\begin{array}{c}\text { Vesicle or } \\
\text { primary hypha }\end{array}$ \\
\hline & & & & \\
\hline \multirow{3}{*}{$\begin{array}{l}U . \text { viciae-fabae } \\
U . \text { vignae } \\
U . \text { appendiculatus }\end{array}$} & $3.3 \pm 0.5^{\mathrm{BC}}$ & $96.5 \pm 1.0^{\mathrm{A}}$ & $0.3 \pm 0.5^{\mathrm{D}}$ & D \\
\hline & $3.3 \pm 2.3$ & $95.5 \pm 1.9$ & $0.3 \pm 0.5$ & $1.0 \pm 1.1$ \\
\hline & $4.5 \pm 2.1$ & $92.5 \pm 2.9$ & 0 & $3.0 \pm 1.1$ \\
\hline \multicolumn{5}{|l|}{$5 \%$ agar } \\
\hline U. viciae-fabae & $3.5 \pm 2.4^{C}$ & $78.3 \pm 2.6 \mathrm{a}^{\mathrm{C}}$ & $14.8 \pm 2.5 \mathrm{a}^{\mathrm{C}}$ & $3.5 \pm 1.9 \mathrm{a}^{B}$ \\
\hline U. vignae & 0 & $13.8 \pm 3.6 \mathrm{~b}$ & $70.0 \pm 4.4 b$ & $16.3 \pm 4.0 \mathrm{~b}$ \\
\hline U. appendiculatus & 0 & $17.5 \pm 7.7 b$ & $50.5 \pm 7.7 c$ & $32.0 \pm 3.7 \mathrm{c}$ \\
\hline \multicolumn{5}{|l|}{ Glass } \\
\hline U. viciae-fabae & $27.3 \pm 8.5 \mathrm{a}^{\mathrm{A}}$ & $4.3 \pm 1.5^{D}$ & $67.3 \pm 6.1 \mathrm{a}^{\mathrm{B}}$ & $1.3 \pm 2.5^{\mathrm{D}}$ \\
\hline U. vignae & $25.3 \pm 4.0 \mathrm{a}$ & $6.3 \pm 2.9$ & $66.0 \pm 1.8 b$ & $2.5 \pm 1.9$ \\
\hline U. appendiculatus & $71.3 \pm 11.9 \mathrm{~b}$ & 0 & $28.7 \pm 11.9 b$ & 0 \\
\hline \multicolumn{5}{|l|}{ Collodion without oil } \\
\hline U. vicia-fabae & $2.8 \pm 1.0^{\mathrm{C}}$ & $30.5 \pm 7.1 \mathrm{a}^{\mathrm{B}}$ & $56.5 \pm 4.4 \mathrm{a}^{\mathrm{C}}$ & $10.3 \pm 2.9 a b^{C}$ \\
\hline U. vignae & $1.0 \pm 0.8$ & $49.0 \pm 11.0 \mathrm{~b}$ & $33.8 \pm 11.6 \mathrm{~b}$ & $16.3 \pm 2.2 \mathrm{a}$ \\
\hline U. appendiculatus & $1.5 \pm 1.0$ & $49.0 \pm 3.4 \mathrm{~b}$ & $42.3 \pm 2.6 b$ & $7.8 \pm 1.7 \mathrm{~b}$ \\
\hline \multicolumn{5}{|c|}{ Nitrocellulose on $5 \%$ agar } \\
\hline U. viciae-fabae & $3.0 \pm 1.6^{\mathrm{BC}}$ & $3.5 \pm 3.3^{\mathrm{D}}$ & $80.8 \pm 6.3 \mathrm{a}^{\mathrm{A}}$ & $12.8 \pm 5.3 \mathrm{a}^{\mathrm{A}}$ \\
\hline U. vignae & $0.3 \pm 0.5$ & $4.5 \pm 2.4$ & $62.3 \pm 4.9 b$ & $33.0 \pm 2.2 b$ \\
\hline U. appendiculatus & $4.5 \pm 1.4$ & $3.5 \pm 2.8$ & $70.2 \pm 5.9 \mathrm{ab}$ & $21.7 \pm 5.3 a$ \\
\hline \multicolumn{5}{|l|}{ Cuticle } \\
\hline U. viciae-fabae & $8.0 \pm 7.1^{\mathrm{B}}$ & $3.8 \pm 3.3 \mathrm{a}^{\mathrm{D}}$ & $75.3 \pm 5.8^{\mathrm{A}}$ & $13.0 \pm 4.8^{\mathrm{C}}$ \\
\hline U. vignae & $5.8+3.3$ & $6.5 \pm 4.2 \mathrm{ab}$ & $75.8 \pm 5.1$ & $12.0 \pm 3.2$ \\
\hline U. appendiculatus & $4.0 \pm 3.2$ & $12.0 \pm 9.5 b$ & $73.8 \pm 17.1$ & $10.3 \pm 6.1$ \\
\hline
\end{tabular}

Note. Data analyzed using Duncan's multiple range test (confidence interval $95 \%$ ). Means with the same letters do not show statistical differences: A, B, C, D refer to the various substrates within each vertical column; $\mathrm{a}, \mathrm{b}, \mathrm{c}$ refer to Uromyces species on the same substrate within each vertical column where differences are significant.

U. vignae generally differentiated infection structures, including vesicles and primary hypha, on the surface of the cuticle (Fig. 9). Infection structures formed in the leaf under natural conditions were compared morphologically to those induced on agar or on artificial membranes. Nuclear condition and septum formation were studied in vitro. Two nuclei were always observed in ungerminated basidiospores (Fig. 10a). During early infection structure development both nuclei migrated together with cytoplasm into the vesicle (Fig. 10b). Subsequently, the penetration peg was plugged and the vesicle grew apically, forming a primary hypha which was sometimes delimited by a septum. Up to the primary hypha stage no more than two nuclei were observed (Fig. $10 \mathrm{c})$.

In the in vivo studies, the fungus was stained with diethanol 3 days after inoculation. In host leaf tissue an intraepidermal vesicle and a branched primary hypha colonized the epidermal cells (Fig. 11). On artificial substrates the basidiospore germlings developed more slowly than in the host epidermis; after 3 days of incubation, only primary hyphae formed. 

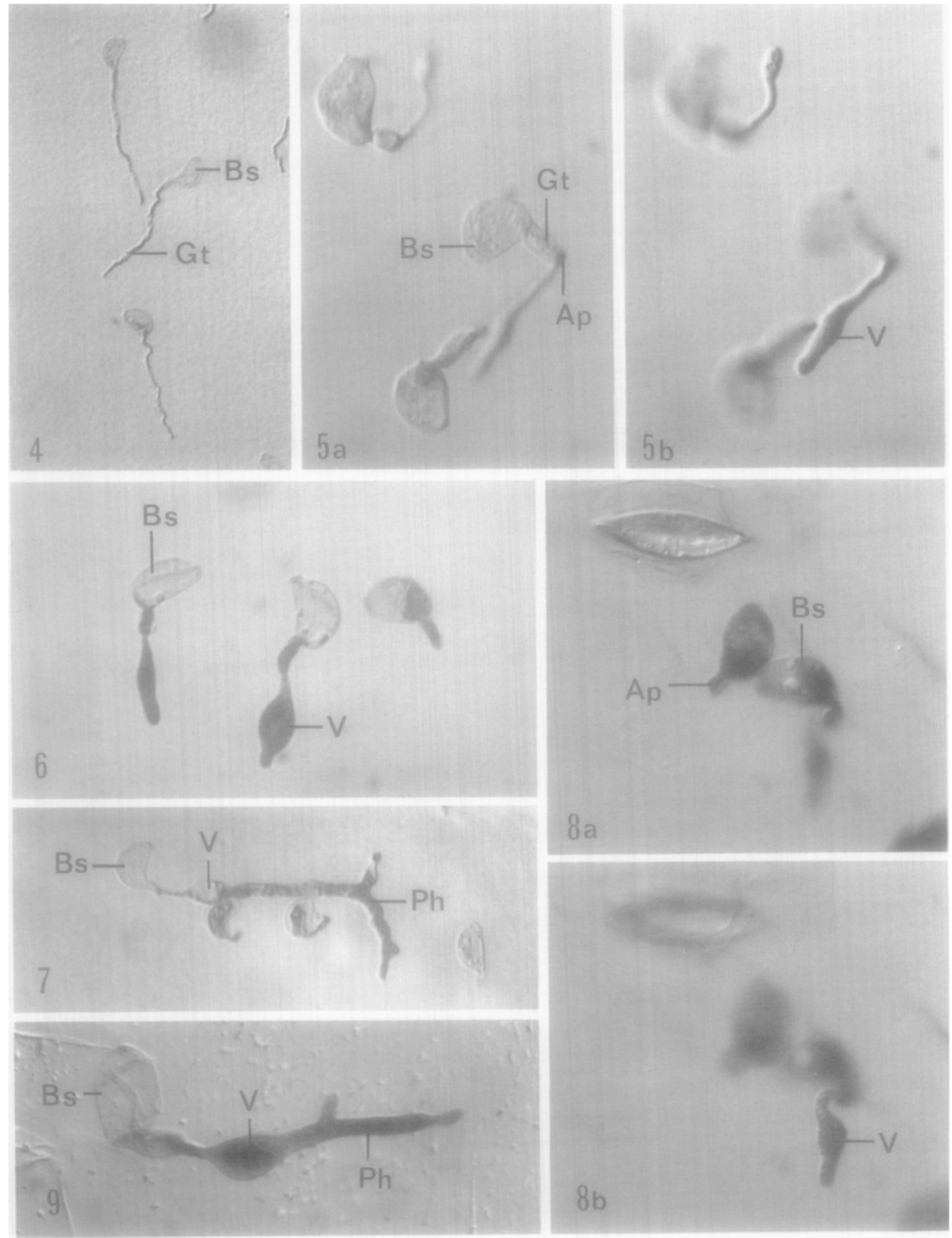

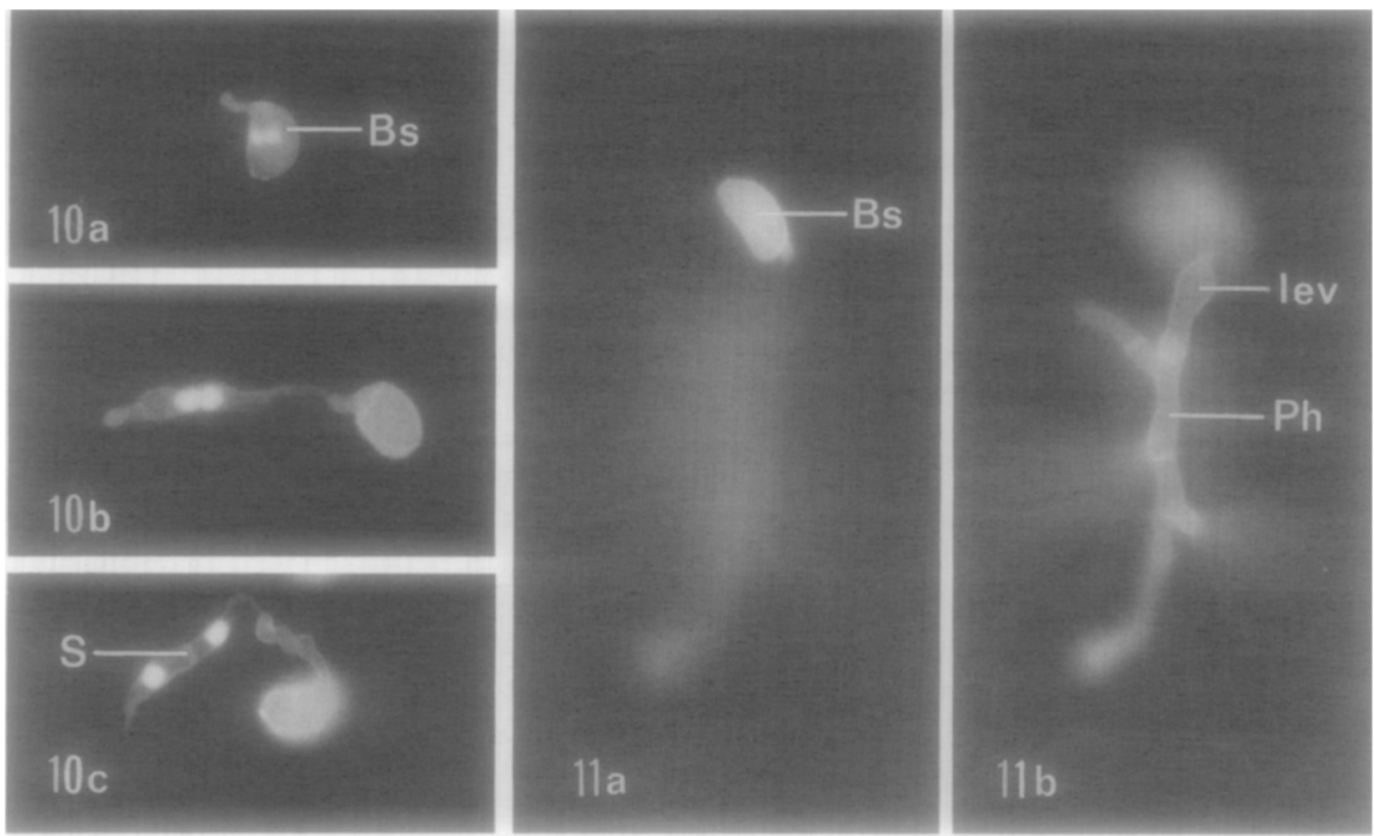

FiG. 10. Nuclear conditions of basidiospores and infection structures of $U$. vignae were observed after staining with DAPI-Calcofluor: (a) the basidiospore is binucleate, (b) the vesicle contains two nuclei, and (c) a septum separates the two nuclei in the infection structure. $\times 500$

Fig. 11. Basidiospore infection structures of $U$. viciae-fabae were stained with diethanol, 3 days after inoculation of host leaf tissue: (a) basidiospore germinates on the leaf surface and (b) differentiate vesicle and primary hypha in the epidermal cell. $\times 500$

\section{DISCUSSION}

Teliospores of rust fungi are reported to germinate under different photoperiod conditions (Mendgen, 1984). For instance, teliospores of $U$. appendiculatus var. appendiculatus require a light-off signal to initiate germination (Gold and Mendgen,
1983). Other rusts require alternating lightdark periods for development (Neuhaus, 1969; Ragazzi and Ferrini, 1978). Teliospores from leptotype rust fungi produce metabasidia in continuous light, continuous dark, or under a daily photoperiod (Bega, 1959; Pady and Kramer, 1971). Teliospores

Frgs. 4-11. Ap, appressorium; Bs, basidiospore; GT, germ tube; Iev, intraepidermal vesicle; Ph, primary hypha; S, septum; V, vesicle. Samples in Figs. 4-9 were stained with trypan blue in lactophenol-glycerol.

FIG. 4. Basidiospores germinated on $2 \%$ water agar with long germ tubes (U. appendiculatus var. appendiculatus). $\times 290$

Frg. 5. Differentiated infection structures of basidiospores on 5\% water agar surface: (a) basidiospores, germ tubes, and appressoria are on the agar surface; (b) focus is on vesicles into the agar (U. vignae). $\times 640$

FrG. 6. Differentiated infection structures of basidiospores incubated on nitrocellulose membranes up to the vesicle stage (U. vignae). $\times 640$

Frg. 7. As in Fig. 6, but basidiospore differentiated up to the primary hypha stage ( $U$. vignae). $\times 440$

FIG. 8. Basidiospore germlings of $U$. viciae-fabae penetrating isolated host cuticle after appressorium formation (a) and developing vesicles between cuticle and agar (b). $\times 640$

FIG. 9. Basidiospore of $U$. appendiculatus var. appendiculatus differentiated up to primary hypha on isolated host cuticle. $\times 800$ 
of $U$. viciae-fabae and $U$. vignae, which are not constitutionally dormant, do not require light as a signal for initiating the germination process.

Basidiospore germlings derived from Uromyces species reported here differentiate infection structures in vitro up to primary hyphae. The morphology and nuclear condition of the infection structures formed in vitro are comparable to those shown previously by other workers with different rust fungi in vivo (Gold and Mendgen, 1984; Gray et al., 1983; Metzler, 1982). Basidiospores form similar infection structures in vitro and in vivo, although differentiation is slower under axenic conditions and infection structures are not intracellular. In fact, 3 days were necessary for primary hyphae to form on artificial membranes, while only $24 \mathrm{~h}$ were required in host tissue.

Hansen and Patton (1975) suggested that vesicle formation in vitro by germlings of Cronartium flaccidum was a result of temperature shocks or changes in osmotic concentrations of the supporting solution. Basidiospores of this species penetrate conifer needles indirectly through stomata and form a vesicle in the substomatal chamber like urediniospores. It is conceivable that stomatal-penetrating rusts, independent of their nuclear condition, develop infection structures when a germ tube encounters a specific surface topography such as a stomate on the epidermis of a host plant, a scratch in a polyethylene sheet, or an oil droplet in a collodion membrane.

Our studies with Uromyces species indicate that the surface consistency of the substrate is critical for basidiospores differentiation. We observed an increase in the percentage of vesicles and primary hyphae on hard substrates, such as 5\% water agar and nitrocellulose sheets. Bauer's (1986) work with basidiospores of the directly penetrating rust fungus, Gymnosporangium clavariaeforme, shows that this fungus differentiates appressoria on glass and on 3.7-7\% water agar, but develops no further infec- tion structures. Similar to Bauer's (1986) findings, we observed that glass clearly induces appressoria formation but not vesicles. On glass it appears that the physicochemical surface characteristics are inhibitory to postappressorial fungal growth. Further, it should be noted that a thigmotrophic stimulus such as oil inclusions or scratched polyethylene sheets did not induce a significant increase in the differentiation rate of basidiospores. This is in contrast to urediniospores which respond to topographical features by developing appressoria and further infection structures (Hoch et al., 1987).

Our results indicate that basidiospore infection structures can be induced in the absence of host chemical substances.

$U$. viciae-fabae basidiospores developed vesicles mainly below the cuticles. It is interesting to note that Vicia faba cuticles are very thick and that they possibly retained their native surface characteristics after enzymatic treatment. This may account for the basidiospore penetration process through the cuticle.

On host leaves appressorium formation of rust basidiospores occurs mainly near the anticlinal wall of epidermal cells (Gold and Mendgen, 1984). Similar observations have been made also in some direction penetrating nonrust fungal spores (Staples and Macko, 1980). In conclusion, it appears that directly penetrating germlings respond to an unspecific stimulus, like the thickness of host cuticle or the hardness of an artificial substrate.

\section{REFERENCES}

BAUER, R. 1986. Basidiosporenentwicklung undkeimung bei Heterobasidiomyceten. Ber. Disch. Bot. Ges. 99: 67-81.

BEGA, R. V. 1959. The capacity and period of maximum production of sporidia in Cronartium ribicola. Phytopathology 49: 54-57.

Dickinson, S. 1949. Studies in the physiology of obligate parasitism. II. The behaviour of the germtubes of certain rusts in contact with various membranes. Ann. Bot. S. N. 13: 219-236. 
GOLD, R. E. 1983. Activation and pattern of teliospore germination in Uromyces appendiculatus var. appendiculatus and basidiospore infection of Phaseolus vulgaris. Doctoral dissertation, Universität Konstanz, Konstanz, Federal Republic of Germany.

Gold, R. E., AND MENDGEN, K. 1983. Activation of teliospore germination in Uromyces appendiculatus var. appendiculatus. I. Aging and temperature. Phytopathol. Z. 108: 267-280.

Gold, R. E., AND Mendgen, K. 1984. Cytology of basidiospore germination, penetration, and early colonization of Phaseolus vulgaris by Uromyces appendiculatus var. appendiculatus. Canad. J. Bot, 62: 1989-2002.

Gray, D. J., Amerson, H. V., and VAN DyKe, C. G. 1983. Ultrastructure of the infection and early colonization of Pinus taeda by Cronartium quercuum f.sp. fusiforme. Mycologia 75: 117-130.

Hansen, E. M., and Patton, R. F. 1975. Types of germination and differentiation of vesicle by basidiospores of Cronartium ribicola. Phytopathology 65: 1061-1071.

HeAth, M. C., and Heath, B. 1978. Structural studies of the development of infection structures of cowpea rust, Uromyces phaseoli var. vignae. I. Nucleoli and nuclei. Canad. J. Bot. 56: 648-661.

Hoch, H. C., Staples, R. C., Whitehead, B., COMEAU, J., AND Wolf, E. D. 1987. Signaling for growth orientation and cell differentiation by surface topography in Uromyces. Science 235: 1659 1662 .
LitTlefield, L. J., ANd HEATH, M. C. 1979. Ulirastructure of Rust Fungi. Acadcmic Press, Now York.

MENDGEN, K. 1984. Development and physioloy of teliospores. In The Cereal Rusts (W. R. Bushnell and A. P. Roelfs, Eds.), Vol. I, pp. 375-398. Academic Press, New York.

Metzler, B. 1982. Untersuchungen an Heterobasidiomyceten (23): Basidiosporenkeimung und Infektionsvorgang beim Birnengitterrost. Phytopathol. $Z$. 103: $126-138$.

Neuhaus, W. 1969. Zur Teleutosporenkeimung von Puccinia sorgi Schw. Zbl. Bakt. II. Abt. 123: 266271.

Pady, S. M., AND KRamer, C. L. 1971. Basidiospore discharge in Gymnosporangium. Phytopathology 61: $951-953$.

RaGazZ1, A., ANd Ferrini, F. 1978. Indagine sulla fertilitá e sulla sporulazione dei teleutoconidi di Cronartium flaccidum (Alb. et Schw.) Wint. Phytopathol. Mediterr. 17: 120-126.

ROHRINGER, R., KIM, W. K., SAMBORSKI, D. J., AND Howes, N. K. 1976. Calcofluor: An optical brightener for fiuorescence microscopy of fungal plant parasites in leaves. Phytopathology 67: 808-810.

Staples, R. C., AND MACKo, V. 1980. Formation of infection structures as a recognition response in fungi. Exp. Mycol. 4: 2-16.

WYNN, W. K. 1976. Appressorium formation over stomates by the bean rust fungus: Response to a surface contact stimulus. Phytopathology 66: $136-$ 146. 